\title{
Hermenegildo Calvelo: un xornalista mestre
}

\author{
(Hermenegildo Calvelo: journalist and schoolteacher)
}

\begin{abstract}
Narciso de GABRIEL Universidade da Coruña

RESUMO: Hermenegildo Calvelo Rabuñal é coñecido fundamentalmente como xornalista, mais tamén exerceu como mestre en dúas escolas públicas da provincia de Pontevedra entre 1890 e 1903. Na primeira (Cuntis) foi expedientado por se lle atribuíren diversas faltas de carácter moral e profesional, aínda que 0 expediente foi sobresido. Ao ser condenado a desterro por un delito de inxurias, tivo que abandonar a localidade, conseguindo mediante permuta á escola Mourente. Neste segundo destino formóuselle outro expediente por non cumprir coas obrigas docentes, que se resolveu coa súa separación definitiva do ensino.
\end{abstract}

PALABRAS CHAVE: Hermenegildo Calvelo, expedientes gobernativos, maxisterio, xornalismo, caciquismo.

ABSTRACT: Hermenegildo Calvelo Rabuñal is known mainly as a journalist, but he also taught at the public schools in the province of Pontevedra from 1890 to 1903. At his first post in Cuntis a procedure was brought against him on charges of moral and professional related offences, although the case was dismissed. Penalized for slander, he was forced to abandon the area. Through an exchange, he took up a post at the school in Mourent. At this second post he was charged with not fulfilling his professional teaching duties, which resulted in his permanent removal from teaching.

KEY WORDS: Hermenegildo Calvelo, government proceduras, teaching, journalism, caciquism.

O noso propósito é presentar e analizar os dous expedientes gobernativos a que foi sometido Hermenegildo Calvelo Rabuñal cando rexentaba as escolas primarias de Cuntis e Mourente (Pontevedra). Estes expedientes refírense ao proceso mediante o cal se comprobaba a existencia de comportamentos irregulares na actuación do profesorado, 
así como ás sancións que no seu caso se lle impuñan. ${ }^{1} \mathrm{Na}$ súa tramitación participaban practicamente todas as instancias da administración escolar. ${ }^{2}$

Deterémonos sobre todo no primeiro deles, por se conservar completo no Arquivo Histórico Universitario de Santiago. Na sección de Documentos (pp. 201-220) reproducimos seis das pezas que o integran -algunhas bastante extensas-, para que poida apreciarse a dinámica seguida neste tipo de procesos disciplinarios. Trátase dun dos expedientes máis voluminosos aos que tivemos acceso.

Hermenegildo Calvelo naceu en Carballo en 1856 e morreu en Ourense en 1918. Cursou estudos eclesiásticos en Santiago de Compostela, aínda que non se ordenou sacerdote. ${ }^{3}$ Posteriormente traballou en tarefas administrativas na secretaría da Universidade de Santiago; en 1882 foi nomeado escribente terceiro, cun salario de 750 pesetas anuais, e en 1886 ascendeu a escribente segundo, cobrando a partir de entón $875 .{ }^{4}$ Durante estes anos fíxose mestre superior, acreditando a suficiencia académica 021 de outubro de $1885,{ }^{5} \mathrm{e}$ tamén solicitou que se lle validasen no ensino secundario algunhas das materias cursadas no Seminario. ${ }^{6}$

\footnotetext{
${ }^{1}$ A bibliografía sobre os expedientes gobernativos instruídos ao maxisterio é moi escasa. Entre os traballos realizados podemos citar os de Ignacio Martín Giménez, "Ser maestro en la España del siglo xix", Historia Social, no. 33 (1999): 3-23, e Antonio Molero Pintado, "Los maestros republicanos: legislación y conflictividad profesional (1931-1936)", Historia de la Educación. Revista Interuniversitaria, no. 16 (1997): 285-302. Esther Cortada Andreu utilizou esta fonte na súa obra Ser mestra a la Catalunya del segle XIX. L'escola pública com a espai professional transgressor (Lleida: Pagès editors, 2006), que seguramente é o mellor retrato trazado en España verbo da mestra decimonónica. Hai xa máis de dúas décadas comecei unha investigación arredor dos expedientes gobernativos en Galicia, que de momento só deu lugar a unha publicación: Elisa e Marcela. Alén dos homes (Vigo: NigraTrea, 2008). $\mathrm{Na}$ actualidade está pendente de revisión por History of Education un artigo titulado "Schoolteachers, social control and professional conflict. Government procedures brought against schoolteachers in Galicia (1859-1910)".

${ }^{2}$ En relación coa configuración da administración escolar pode consultarse Manuel de Puelles Benítez, Educación e ideología en la España contemporánea (Madrid: Tecnos, 2010). En Leer, escribir y contar. Escolarización popular y sociedad en Galicia (1875-1900) (Sada: Ediciós do Castro, 1990) analizamos o funcionamento das diferentes instancias da administración escolar en Galicia durante o período que aquí nos ocupa.
}

${ }^{3}$ Antonio Couceiro Freijomil, Diccionario bio-bibliográfico de escritores (Santiago: Bibliófilos Gallegos, 1951), I, 199-200.

${ }^{4}$ Expediente persoal de empregado administrativo, Arquivo Histórico Universitario de Santiago (en adiante, AHUS), Fondo Universitario, Serie Histórica, caixa 333, expediente 47.

${ }^{5}$ Antonio Couceiro Freijomil escribiu no diario compostelán La Noche (13 de abril de 1951) que, ao morrer Calvelo, atopou nun caixón da mesa de redacción de El Diario de Orense o título de mestre deste, e que se quedou con el, porque ninguén mostrou interese en conservalo.

${ }^{6} \mathrm{O} 15$ de outubro de 1885, o reitor Antonio Casares trasladou ao ministro de Fomento unha instancia de Calvelo solicitando que se lle recoñecesen "como ganadas en enseñanza oficial las asignaturas de $2^{\mathrm{a}}$ enseñanza que ha cursado y aprobado en el Seminario conciliar de esta Ciudad." O Seminario presentara na secretaría da Universidade un escrito pedindo "su asimilación al Instituto, y se halla ya inscrito como asimilado; siendo pues válidos como oficiales los estudios que de aquí en adelante se hagan en él, parece equitativo que también tengan igual validez los que se han hecho en los cursos anteriores, y por consiguiente que V. E. pueda conceder al Sr. Calvelo Rabuñal la gracia que solicita" (Expediente persoal de empregado administrativo). Non sabemos se se accedeu ao solicitado, o que suporía aplicar a lei con carácter retroactivo. 
O 30 de xuño de 1890 renunciou ao emprego na secretaría da Universidade, por ter gañado en "reñidas oposiciones, a las que se presentó con sólo veintitrés días de preparación", a escola elemental completa de nenos da vila de Cuntis. ${ }^{7}$ Estaba dotada con 825 pesetas anuais, o que a situaba entre as mellor remuneradas de Galicia. ${ }^{8}$ Eran 25 pesetas menos das que recibía como escribente segundo, pero como mestre público tiña dereito a casa para vivir e ás retribucións dos nenos cuxas familias fosen consideradas "podentes", malia non seren sempre doadas de cobrar. Da escola de Cuntis pasou en 1897 á de Mourente, onde permanecerá ata 1903.

Aínda que traballou durante un tempo como mestre, don Hermenegildo seguramente se consideraba máis que nada xornalista, exercendo como tal nas cidades de Santiago de Compostela, Pontevedra, Vigo e Ourense. En El Libredón (Santiago) publicou en 1885 os seus Discursos sobre Metafísica. ${ }^{9}$ Tamén pronunciou diversas conferencias acerca de temas de carácter filosófico, relixioso ou social. ${ }^{10}$

O retrato que de Calvelo nos ofrece Joaquín Arias Miranda (asina como Jorge Bruhmel) ábrese coa descrición que os naturalistas fan do can de Terranova, pois o físico daquel lembraba o deste. Bruhmel dicía ignorar a razón de tal semellanza, mais podía asegurar que "nació de vientre de mujer y que, dentro de su envoltura perruna, alienta un espíritu inteligente, cultivado, lleno de bondad, ahíto de sabiduría." E contiuaba:

El rostro, llamémosle así, de D. Hermenegildo Calvelo, ha sentido ya las cálidas caricias del sol de cincuenta estíos y los soplos del aire de cincuenta inviernos. En la languidez de sus ojos se refleja el prestigio de un alma mirífica y sentimental y en la amplitud de su frente hay como el resplandor de un cerebro privilegiado.

D. Hermenegildo siguió, en sus años mozos, la carrera eclesiástica en el Seminario Conciliar de Santiago de Compostela. Él sentía una gran vocación hacia esa carrera. Pronto iba a ordenarse. Pero un día quiso el azar que, al discurrir por las viejas rúas santiaguesas, sus ojos tropezaran con el milagro de unos ojos de mujer. Comenzó el amor, desde entonces, a espandirse [sic] en su alma como en las noches estivales se espanden [sic] los aromas. Y D. Hermenegildo acabó por renunciar al sacerdocio para unirse santamente con quien supo esclavizar su corazón de niño. [...]

Espíritu profundamente místico, empapado en las doctrinas sublimes de la religión cristiana, él no podía contemplar serenamente el espectáculo que la impiedad empezaba entonces a ofrecer. Quiso combatir a los herejes, a los que con sus golpes formidables intentaban la disparatada empresa de derrocar el hermoso edificio de la Santa Iglesia Católica.

\footnotetext{
7 Jorge Bruhmel, "Periodistas vigueses. D. Hermenegildo Calvelo", El Correo Gallego (Ferrol), 17 de marzo de 1909.

${ }^{8}$ A folla se servizos, así como o resto dos documentos que se citen neste apartado, están depositados, sempre que non se sinale outra procedencia, no AHUS, Ensino primario, caixa 171.

${ }^{9}$ Gonzalo Díaz Díaz fíxose eco destes Discursos en Hombres y documentos de la filosofía española (Madrid: CSIC, 1983), II. 44. Alfredo Brañas, pola súa parte, escribiu que Calvelo "demotró sus profundos conocimientos filosóficos en sus Discursos sobre metafísica que imprimió El Libredón”. El Regionalismo (Barcelona: Jaime Molinas Editor, 1889), 347.

${ }^{10}$ Dous exemplos: en 1884 disertou sobre o matrimonio civil na Academia da Xuventude Católica de Santiago, da que ao parecer era vicepresidente (Galicia Católica-Santiago-, 14 de abril de 1884), e en 1897 sobre a alma humana no Círculo Católico de Pontevedra (Gaceta de Galicia-Santiago-, 27 de febreiro de 1897).
} 
Alistose en las filas de los paladines del periodismo. Publicó unos artículos valientes y demoledores en varios periódicos santiagueses. Aquellos artículos eran leídos con avidez y rodearon a su autor de una aureola de prestigio. ${ }^{11}$

\section{Cuntis}

O noso home aterrou na vila de Cuntis, famosa polos benéficos efectos das súas augas, 01 de xullo de 1890, en plena tempada de baños. A de 1892 foi boa, segundo informaba o correspondente da Gaceta de Galicia na localidade: "La fonda de la Virgen está llena y tiene bastante gente la de Barreiro y alguna menos la de Amelia." Entre os visitantes dese ano contábase Joaquín López Puigcerver, ex-ministro de Facenda, que fora recibido con entusiasmo polos seguidores de Montero Ríos. A crónica tamén aludía a Calvelo, que viña de publicar unha carta en El Pensamiento Galaico de Santiago de Compostela. Nela limitábase a copiar, continúa o correspondente, unha memoria do doutor Casulleras, médico do balneario, sobre a composición e as aplicacións das augas da vila, e aproveitaba a ocasión para insultar a un dos bañistas, moi querido na localidade. ${ }^{12}$ Parece, pois, que don Hermenegildo non tardou moito en trabar as polémicas ás que tan dado era, como iremos vendo.

Cando xa transcorreran catro anos desde a súa chegada á vila, concretamente 016 de xullo de 1894, Salvador de J. Ponsoda, inspector de ensino primario da provincia de Pontevedra, informou a Maximino Teijeiro, reitor da Universidade de Santiago, do resultado da visita que lle ordenara facer á escola de nenos de Cuntis. Os resultados obtidos na instrución dos nenos eran "bastante satisfactorios", e aínda que a conduta moral do mestre, Hermenegildo Calvelo, fora "objeto de las miras del pueblo con razón más o menos fundada, en atención a hallarse separado de su esposa", na data en que redactaba o informe "no hay motivo alguno de censura bajo este concepto; pues si bien es verdad que tiene de doméstica a una muchacha, no da motivo ni lugar a que se le tilde en lo más mínimo". Advertía, no entanto, que "con motivo de significarse en política, está mal visto por algunas personas adictas al partido contrario; y quizá sea ésta la principal causa de la queja producida a ese Rectorado."

As noticias de que dispuña Maximino Teijeiro non eran esas, polo que un mes máis tarde ordenou á Xunta provincial de Instrución pública que se abrise un expediente gobernativo para determinar as responsabilidades en que puidese ter incorrido o mestre. A orde foi transmitida pola Xunta provincial ao alcalde de Cuntis.

Os oito veciños chamados a declarar polo alcalde deron fe da boa conduta moral, relixiosa, política e profesional do mestre. Sirva como exemplo o testemuño do veterinario, Antonio Abal, segundo o cal o investigado "disfruta de intachable conducta moral y política y atiende con perfecto celo al desempeño de su cargo de Profesor de Instrucción primaria, por cuyo motivo es acreedor a todas las consideraciones sociales, como generalmente

\footnotetext{
11 Jorge Bruhmel, "Periodistas vigueses. D. Hermenegildo Calvelo".

12 Gaceta de Galicia (Santiago), 9 de setembro de 1892.
} 
se reconoce." Ademais destes oito veciños, tamén emitiron informes favorables o párroco, Isolino Suárez, o fiscal municipal, Vicente Carballo, e a Xunta local de ensino primario. Só discrepaba deste parecer o xuíz muicipal, Joaquín Barreiro García, segundo se pode ler no Documento 1.

Unha vez practicadas as dilixencias solicitadas, a autoridade local remitiunas á provincial, mais esta devolveu o expediente á alcaldía para que fosen chamadas a declarar as persoas ás que aludía no seu escrito o xuíz municipal; os seus testemuños espontáneos debían ser rexistrados "con entera imparcialidad".

Pois ben, das dez persoas aludidas polo xuíz que prestaron declaración, cinco fíxérono en contra e outras tantas a favor do mestre, nalgún caso con matices. As primeiras acusábano de que "tiene la escuela completamente abandonada" (José Fariña Barreiro), ou cando menos "esquiva con frecuencia las horas de clase" (Nicolás García Garrido), polo que algúns pais retiraran os fillos da escola pública e inscribíranos na privada; fora abandonado pola súa nai, á que non trataba coa corrección debida; e era afeccionado á bebida, frecuentando tabernas e cafés. As segundas nada tiñan que obxectar á súa conduta moral e profesional ou considerábanas boas, malia que José Lajos Fraga ouvira "que fuera de las horas de clase frecuenta el café, aunque no oyó decir que se embriague nunca", e José Hermo García sabía por referencias que algúns nenos trocaban a escola pública pola particular.

011 de outubro o alcalde remitiu de novo o expediente á Xunta provincial, que llo fixo chegar ao inspector para que emitise o informe correspondente. Salvador de J. Ponsoda, despois de resumir o contido dos testemuños que contiña, os máis deles favorables a don Hermenegildo, conclúe que é "competente", non ten a escola "tan abandonada" como algúns afirman e "existe animosidad" contra el por parte dalgúns veciños, polo que propón o sobresemento. A súa proposta foi asumida pola Xunta provincial. ${ }^{13}$

Mentres se realizaban estas dilixencias, o expedientado emprendeu diversas accións para defenderse dos cargos que se lle apuñan, mais tamén para atacar os seus inimigos. Con este segundo propósito publicou varios artigos en La Unión Republicana de Pontevedra, xornal cuxas ideas político-relixiosas declaraba non compartir, e co que polemizará duramente andando o tempo, cando exerza o cargo de director do xornal El Áncora. Como sostiña Alfredo Brañas, o noso home era "invencible en la pelea, [e] terrible en la miscelánea política", ${ }^{14}$ aínda que seguramente non foi nesta ocasión cando a súa pluma voou a maior altura.

No primeiro dos artigos afirma que antes de chegar a Cuntis só coñecía dúas castes de caciquismo, o despótico e o protector, baseados, respectivamente, na forza e no afecto. Nesta vila comprobou que existía outra modalidade, que cualifica de caciquismo culinario, "porque despide cierto olor a guiso y un tufillo de sacristía que da náuseas". O grupo de no-

\footnotetext{
${ }^{13}$ A decisión da Xunta provincial, datada 022 de outubro de 1894, está no AHUS, Ensino primario, caixa 121.

${ }^{14}$ Alfredo Brañas, El Regionalismo, 347.
} 
tables reducíase a cinco persoas, emparentadas e privadas do poder municipal. Estaban representados por José Fariña Barreiro, no seu día emigrante na Habana, onde exercera oficios "serviles", e na actualidade propietario dunha fonda en Cuntis e arrendatario dos baños da Virxe. Fora procesado por inxuriar e calumniar a unha señora, era un cazador incansable e a súa forza física resultaba temible. "Cuando está alegre, y en invierno lo está con frecuencia, muestra un mal humor y un geniazo irresistible, jcosa más rara!" Sobre Eugenio Aboy García non era moito o que tiña que dicir, se ben deixa constancia de que fora procesado por falsidade documental, aínda que resultara absolvido debido aos bos oficios dun avogado. "D. Nicolás Garrido García es un jigante [sic] y el presbítero más fecundo del distrito: consigue frutos de bendición en donde otros, a fuerza de machacar, no obtienen raja. [...] Es también el mejor jinete del país, y no hay devota, aficionada a ejercicios corporales, que no admire su robusta organización y la gallardía con que monta." Desatendendo as ordes das autoridades eclesiásticas, que prohibían aos sacerdotes inmiscirse en liortas políticas, interviña activamente a prol dos candidatos liberais en todos os procesos electorais. Por último, Pedro Castro Rivas, presbítero como o anterior, e que na súa mocidade "montó con tanta destreza como él", acababa de financiar a viaxe a América dun fillo de moza solteira e fora condenado xudicialmente por desacato á autoridade. Para completar o quinteto só restaba un integrante, pero ese, en atención a que era o máis letrado e desempeñaba un modesto cargo público, merecía un artigo específico. Tratábase de Joaquín Barreiro García, o xuíz municipal a quen xa coñecemos. ${ }^{15}$

No expediente gobernativo non aparece 0 artigo dedicado a este, aínda que si o publicado 030 de novembro de 1894. Nel infórmase que o primeiro merecera unha demanda por inxurias, mais non así o segundo, que supoñemos trataría, como estaba previsto, sobre Joaquín Barreiro García. É posible que este segundo escrito fose menos agresivo.

$\mathrm{O}$ acto de conciliación, convocado como paso previo á querela criminal que tiñan previsto presentar as catro persoas que se sentían inxuriadas polo primeiro artigo publicado en La Unión Republicana -representadas precisamente por Joaquín Barreiro García-, celebrouse 014 de novembro de 1894. O demandado considera improcedente a demanda, por non estar debidamente formulada, como probaría no seu momento. Manifesta o seu abraio polo feito de que os demandantes, ao unísono, "y como si los cuatro formasen una sociedad de seguros contra injurias", percibisen aldraxes nun texto que se axustaba estritamente á verdade, tanto na súa letra como no seu espírito. "Por el contrario, hay elogios, que si por exajerada [sic] modestia de dichos señores no los aprecian así, pudieran a lo más considerarlos como hipérboles o alabanzas poco justificadas." Quen fora realmente inxuriado e calumniado polos demandantes era el, segundo se desprendía das declaracións prestadas por estes no expediente gobernativo que se lle estaba a instruír.

Concluído sen acordo 0 acto de conciliación, os agraviados presentaron querela criminal por inxurias graves no xulgado de primeira instancia de Pontevedra, que decidíu

${ }^{15}$ Hermenegildo Calvelo, "Desde Cuntis", La Unión Republicana (Pontevedra), 8 de novembro de 1894. 
procesar o mestre o 6 de decembro. Así llo comunicou o xuíz ao reitor, contestando a un oficio deste, 0 día de fin de ano de $1894 .^{16}$

Se nun primeiro momento só testemuñaron en contra de Calvelo cinco individuos -os aludidos nos artigos publicados en La Unión Republicana-, o 23 de decembro de 1894 fixérono 64. Ese día presentouse na vila de Baños de Cuntis, a requirimento de José da Riba Fojo, agrimensor e propietario, José Casal, notario de Moraña, para dar fe dun escrito dirixido ao reitor da Universidade de Santiago. Dicía así:

Que por desgracia de la enseñanza tienen en esta Villa un Maestro de la Escuela completa el cual se entrega a tan grandes excesos que solo teniendo perturbada su razón se puede concebir lo que está pasando. El expresado Maestro D. Hermenegildo Calvelo, adquirió la enemistad de casi todos los vecinos, hasta el punto de no concurrir a su Escuela sino un reducido número de niños por tenerla abandonada, y dedicarse al feo vicio de la borrachera y a escribir en el desprestigiado periódico pontevedrés, "La Unión Republicana", en cuyas columnas el citado Maestro vomita las más graves injurias contra honradísimos vecinos de Cuntis. - Hace poco que la Junta provincial de Instrucción pública sobreseyó un expediente gubernativo que debe existir en ese Rectorado, y cuyo sobreseimiento obedece a que el actual Inspector de Escuelas cuando vino a Cuntis, no tomó con empeño el cumplimiento de su misión, ni trató de indagar con verdadera imparcialidad y justicia cuantos hechos graves ha cometido el aludido Maestro. El citado Inspector en unión de este Ayuntamiento, o mejor aún, de las contadas personas que en Cuntis protegen al Sr. Calvelo, instruyeron una farsa de expediente en la cual no se oyó a los que iban resueltos a decir la verdad, atemorizándoles para esto, y en cambio depusieron algunos que, para que V. E. vea la libertad que tenían para declarar, firman esta instancia, acusando al Maestro D. Hermenegildo Calvelo, cuyo desprestigio llega hasta el punto de adeudar en varios establecimientos de bevidas [sic] cantidades relativamente de consideración.

Os abaixo asinantes, dos que cinco eran mulleres e 15 non asinaban por seren incapaces de facelo, concluían solicitando ser liberados do mestre que tiñan e que se lles asignase outro que "enseñe y eduque a nuestros hijos".

Idéntica petición trasladou ao reitor, tres días despois e a título individual, José Mํㅡㄴ Lorenzo, que se presentaba como "Rector párroco de Palmillas, provincia de Matanzas en la Isla de Cuba, propietario en la Villa de los Baños de Cuntis, y con residencia accidental en ella". Animado polo desexo de contribuír á difusión das luces no seu país de orixe, decidira asumir os gastos ocasionados pola "educación literaria de seis niños huérfanos y pobres de solemnidad". Mais para facer realizade este benéfico propósito tropezaba cun primeiro atranco: 0 deficiente comportamento do mestre da vila, tanto no plano profesional -o seu celo polo ensino estaba "tan apagado" que podería afirmarse que "es la menor cantidad posible de Maestro"- como moral - "sería prolijo enumerar" os "vicios que le dominan".

Atendendo ás "gravísimas quejas" presentadas por "muchos vecinos" de Cuntis, o reitor acordou suspender o mestre de emprego e medio soldo, como adoitaba facerse cando se estimaba que os cargos eran de peso e existían indicios de culpabilidade (29 de decembro de 1894). Asemade, solicitou a Tomás Luciano Carreira, inspector coruñés -0

${ }^{16}$ AHUS, Ensino primario, caixa 121. 
pontevedrés estaba acusado, como xa sabemos, de parcialidade-, que se desprazase a Cuntis para informar sobre os feitos (8 de xaneiro de 1895). ${ }^{17}$

Tomás Luciano Carreira elaborou un extenso e ben redactado informe, que reproducimos na súa integridade e merece ser lido (Documento 2). Para a súa elaboración entrevistouse co párroco e outros individuos respectables, que informaron favorablemente sobre a conduta moral e profesional do mestre. Tamén estimou conveniente tomar declaración oficial a seis persoas con fillos ou parentes na escola: catro pais, unha nai -por ausencia do marido- e o irmán de tres nenos orfos. Todos eles manifestaron estar satisfeitos dos progresos realizados polos seus fillos ou irmáns e acreditaban o celo e moralidade do mestre, ou cando menos nada tiñan que dicir na súa contra. Tan só Antonio Abal recoñecía que ouvira "alguna vez que se embriaga y es jugador", mais non daba crédito a esa imputación porque "procedía de personas conocidamente enemigas del Sr. Calvelo."

O inspector coruñés concluía que as acusacións eran infundadas e estaban promovidas polos inimigos do mestre. No tocante á instancia asinada perante notario por 64 veciños, debería ser remitida aos tribunais de xustiza, entre outras razóns porque algúns dos que a subscribiran cometeran perxurio.

Procedería, xa que logo, repor o mestre na escola e sobreser o expediente, se o ben do ensino non reclamase o seu traslado a outra localidade, pois contaba en Cuntis con importantes adversarios, que dificilmente esquecerían o retrato que deles se fixera nas páxinas de La Unión Republicana. Esta medida -típica nos casos de incompatibilidade- non debería prexudicar o interesado na súa traxectoria profesional.

01 de febreiro de 1895, Maximino Teijeiro enviou á Xunta provincial o expediente, "con los nuevos antecedentes promovidos por el Rectorado", para que informase o máis axiña posible acerca da resolución que conviña adoptar. E a Xunta, atendendo á conduta "poco correcta" do mestre, ao publicar artigos xornalísticos ofensivos para persoas "caracterizadas de la localidad", coas que se fixera "incompatible", así como ás acusacións contidas na acta notarial, ${ }^{18}$ propuxo o seu traslado forzoso a unha escola da mesma categoría e soldo fóra da provincia (13 de marzo de 1895).

Antes de someter o asunto ao Consello universitario, órgano asesor do reitor en materia disciplinaria, este encomendou ao director da Escola Normal de Santiago que o examinase e redactase unha proposta de resolución. Mais Gorgonio Hueso, que así se chamaba o relator, observou que non se formara o prego de cargos, que era preceptivo facer chegar ao imputado para que tivese a oportunidade de defenderse. De modo que o expediente foi remitido de novo á Xunta provincial, e era a cuarta vez que se facía (26 de marzo de 1895). Ao mesmo tempo, Maximino Teijeiro deixou sen efecto a suspensión de emprego e medio soldo do mestre, que recuperou a súa escola (1 de abril de 1895).

\footnotetext{
17 Ibid.

${ }^{18}$ Sorprende que a Xunta, malia ter no seu poder o informe do inspector coruñés, non reparase nas inconsistencias da acta notarial.
} 
O prego de cargos redactado pola Xunta provincial era o seguinte (1 de xuño de 1895):

$1^{\circ}$ Que desde que se hizo cargo de la Escuela vino pasando la mayor parte del tiempo en la Taberna de José de la Fuente, su convecino, saliendo de ella bastante tarde, y muchas veces contento, continuando en la actualidad ese género de vida en el Café de D. Antonio Rivas Sueiro.

$2^{\circ}$ Que vive separado de su esposa, a la cual tiene completamente abandonada: que su Sra. madre, no pudiendo consentir dignamente la permanencia en su casa de una joven doméstica, tuvo que retirarse a vivir al lugar de Rojos, inmediato a la Ciudad de Santiago, en compañía de familia extraña.

$3^{\circ}$ Que se le dio una cencerrada por la conducta que vino observando.

$4^{\circ}$ Que abandonó la enseñanza dedicando las horas reglamentarias [a pasear] con sus íntimos, y cuando no [está] en sus habitaciones particulares, por cuyos motivos algunos padres de familia tuvieron que mandar sus hijos a Escuelas particulares.

5 Que publicó en el diario "La Unión Republicana" una serie de artículos depresivos para algunos de sus vecinos.

A resposta foi extensa -ocupa 27 páxinas-, contundente, consistente e, en principio, convincente (Documento 3). 0 acusado desvirtúa o primeiro cargo, ${ }^{19}$ afirma que foi a súa muller quen o abandonou a el, declara que vive coa súa nai, nega a existencia da choca$\|{ } \mathrm{dda}^{20}$ e rebate o presunto abandono do ensino. En relación co quinto, alega o seu dereito a defenderse das persecucións de que é obxecto.

Antes de informar de novo o expediente, o inspector pontevedrés fixo saber ao presidente da Xunta provincial que debía concederse ao mestre un prazo para presentar probas na súa defensa, como este solicitaba no seu escrito de descargo, pois tamén se accedera a incorporar ao expediente os testemuños adicionais promovidos polo xuíz municipal. A corporación provincial así o fixo, establecendo un prazo de 30 días para "justificar las contestaciones" ao prego de cargos, e determinando que as probas debían ser presentadas no xulgado municipal de Cuntis.

A estes efectos, o mestre entregou a Joaquín Barreiro a listaxe de persoas que citaba a declarar, entres as cales se achaba o propio xuíz municipal, que quedaba, xa que logo, inhabilitado para exercer como tal na declaración testemuñal. Barreiro advertiu á Xunta provincial que tamén foran chamados a declarar os posibles xuíces suplentes, e que Calvelo pretendía interrogar persoalmente a todas as testemuñas nos termos que estimase

\footnotetext{
${ }^{19}$ En relación con este cargo, relativo á súa suposta afección á bebida, Eduardo Blanco Amor, que foi secretario de redacción de El Diario de Orense cando o dirixía Calvelo, lembraba así o seu xefe nunha entrevista realizada en 1954: "Lo dirigía un viejo fraile exclaustrado y borrachín. Bebía el aguardiente inspiratriz en un vaso de agua para que creyesen que era agua." Segundo Victoria A. Ruiz de Ojeda, editora do libro que recolle esta e outras entrevistas, Blanco Amor cobraba da Deputación provincial en concepto de ama de cría, e asinaba os recibos das nóminas como Herminia Fernández de Príamo. Parece ser que o director de El Diario tamén estaba na nómina da Deputación como suposto xardineiro maior. Entrevistas con E. Blanco Amor (Vigo: Nigra, 1994), 22. Resulta un tanto sorprendente, dada a natureza da obra, que Antonio Couceiro Freijomil escribise o seguinte sobre 0 xornalista-mestre no seu Diccionario bio-biliográfico: "En sus últimos años habíase entregado a los placeres alcohólicos" (p. 200).

${ }^{20}$ Sobre as chocalladas como mecanismo de censura social, cfr. Xavier Castro, Historia da vida cotiá en Galicia. Séculos XIX e XX (Vigo: NigraTrea: 2006), 321-353.
} 
oportunos, así que, ao seu entender, a Xunta debería nomear a un dos seus vogais para recibir a información. A súa proposta foi aceptada, designándose a Miguel Nine para practicar as dilixencias. Este debía fixar lugar, día e hora, e solicitar ao mestre a relación de preguntas que quería formular, sobre cuxa pertinencia decidiría o vogal-delegado, que tamén quedaba facultado para "adoptar todas las medidas que crea convenientes y que tiendan al mayor esclarecimiento de los hechos que se persiguen."

Tres días despois, Nine comunicou a Calvelo que as declaracións se realizarían no Pazo da Deputación provincial de Pontevedra, iniciándose o día 7 de outubro de 1895, en que serían interrogadas as 10 primeiras testemuñas, e continuando os días $8,9,10,11$, $12,14,15,16,17$ e 18, a razón de dez persoas por día; advertiuno, asemade, que previamente debería presentar por escrito o interrogatorio que desexaba formular.

O mestre, pola súa parte, oficiou á Xunta provincial para facerlle saber que o xuíz municipal mentía -e reservábase a posibilidade de denuncialo por falsidade documental- ao afirmar que non existían persoas que o puidesen substituír no cargo, pois o avogado Manuel Castro ou o propietario José Soto podían facelo, como xa o fixeran noutras ocasións, e que recusaba a Miguel Nine, malia ser "persona de extremada rectitud y delicadeza", por cinco razóns, que no fundamental se resumían nunha: era amigo íntimo dos seus inimigos, referindo, para probar o aserto, diversos feitos que ao seu entender así o evidenciaban. Polo demais, convocar as súas testemuñas en Pontevedra supuña privalo de defensa, pois el non podía obrigalas a desprazarse ata a capital provincial; caso de se presentar algunha, seguramente serían as de cargo. Por todo 0 anterior, solicita que se derrogue 0 acordo adoptado, baseado en datos falsos, e se permita recibir a información no xulgado ou na alcaldía de Cuntis, coa presenza fiscalizadora dun vogal da Xunta provincial que non fose Nine, e concedéndolle ao propio mestre a posibilidade de interrogar as testemuñas (28 de setembro de 1895).

Transcorridos dous días, Calvelo trasladou a Nine a súa decisión de recusalo. Este contestou que, "en uso de las facultades que la Junta me ha conferido", desestimaba a recusación, por considerar que carecía de fundamento, e que, se o estimaba oportuno, solicitaría información adicional a persoas da "mayor probidad y arraigo" na localidade (4 de outubro de 1895). Polo de pronto, ese mesmo día escribiu ao xuíz municipal de Santiago para que tomase declaración á muller de Calvelo e a Manuel Ballesteros, anterior párroco de Cuntis, residentes ambos nese concello.

Calvelo retrucou a Nine que, mentres a Xunta provincial non resolvese acerca da recusación e da petición formuladas, "me abstendré de presentar pruebas de ningún género, y protestaré respetuosamente contra todo acto que V. practique considerándole nulo, y reservándome el derecho de queja", porque "ningún juez recusado resuelve la recusación"; insistía en que estaba unido a José Fariña e Joaquín Barreiro por "afecto e interés político de localidad" -semella que os tres pertencían ao Partido Liberal-, e concluía que o seu escrito daba a impresión de que pretendía "practicar" máis que "recibir" información (8 de outubro de 1895). 
O 11 de outubro compareceu no xulgado de Cuntis o vogal designado pola Xunta provincial para realizar as dilixencias acordadas. 0 mestre, presente na sala, negouse a achegar o papel timbrado que se lle pedía, co propósito de rexistrar as declaracións, e dixo que non o faría, nin tampouco presentaría testemuñas, mentres non se resolvese a recusación e se lle desen as garantías necesarias, non só para recibir información, senón tamén para ter a oportunidade de "aclarar las falsedades cometidas por los que aparecen firmando una queja dirigida al IImo. Sr. Rector" -esta era unha das razóns polas que solicitaba con insistencia a facultade de formular directamente as preguntas-. Tamén pedía ser ouvido no seo da corporación provincial.

Mais Nine, procurador de profesión, xa procurara outras persoas dispostas a declarar. Fixérono o propio día 11 cinco mulleres e tres homes -sorprende o desequilibrio a prol das mulleres neste tipo de actuacións-, e as súas declaracións foron polo regular desfavorables ao imputado, tanto no plano moral como, e especialmente, no profesional. A máis contundente resultou ser a de Manuela García Garrido: Calvelo emborrachábase, tiña abandonada a súa esposa, inxuriaba e maltrataba a súa nai -ela mesma tivera a oportunidade de comprobalo- e desatendía a escola, como testemuñarían "todos los vecinos de Cuntis si estubieran [sic] dispuestos a decir la verdad." A máis relevante foi a de Baldomero Piñeiro, que substituíra ao expedientado cando este estivera suspendido de emprego e medio soldo, e segundo o cal, con el á fronte da escola, a matrícula ascendera nun mes de 9 a 72 alumnos, datos que, de seren certos, constituirían un claro indicio do escaso celo do mestre titular.

O vogal-delegado informou da súa misión ao gobernador civil, ao que se dirixe na condición de tal, e non como presidente que era da Xunta provincial. Recoñecía que, ao se negar Calvelo a presentar as probas de descargo perante el, "debía dar por terminada mi misión, considerando subsistentes en toda su fuerza los puntos que comprende el pliego de cargos. Sin embargo, mi deber era investigar la verdad para convencerme si a ese profesor se le perseguía injustamente, o si existían motivos racionales para considerarle indigno de desempeñar el cargo." Engadía que, de seren outras as testemuñas, unhas defenderían o mestre e outras atacaríano, quer por causas fundamentadas, quer por liortas locais. "Pero lo que Calvelo no había de desvirtuar aunque a su favor declarasen los 108 testigos de la lista, era un cargo gravísimo que contra él resulta. Los comunicados que suscribe y hace suyos, insertos en el periódico "La Unión Republicana" de 8 y 30 de noviembre de 1894, revelan una saña y enemistad profunda contra varios vecinos de Cuntis", e neles "insulta de una manera escandalosa y con publicidad a dos venerables sacerdotes", que "representan aquí en la tierra la sublimidad de Jesucristo y aunque fueran, que no son, sacerdotes de malos antecedentes, nadie debiera hacer alarde ni publicar con escándalo sus faltas, mucho menos un maestro de escuela, que debe ser siempre modelo de virtud si ha de dar ejemplo a sus discípulos" (30 de outubro de 1895).

Nine concluía afirmando que desempeñara "fielmente y sin apasionamiento" o encargo que se lle fixera. Quen isto escribe ten dúbidas de que así fose. 0 empeño que puxo en practicar a proba solicitada, resolvendo el mesmo a recusación de que fora obxecto, resulta sospeitoso. 
Engadir novas probas de cargo nunha fase de descargo supuña desnaturalizar a posibilidade de defensa concedida ao mestre. Por último, valorar o alcance dos cargos -nomeadamente 0 quinto- e converterse en xuíz non era precisamente a misión que lle fora encomendada.

A Xunta provincial seguramente chegou a unha conclusión similar, pois encargou ao exxuíz municipal Manuel Castro de recibir as declaracións solicitadas. Castro preguntou á superioridade se o mestre podía estar presente durante as declaracións das testemuñas e formular directamente as preguntas que estimase convenientes, ao que a Xunta contestou que si ao primeiro extremo e non ao segundo: Calvelo só tería a facultade de comunicar ao xuíz as preguntas que desexaría formular, e este así o faría, desbotando as que estimase improcedentes.

As declaracións iniciáronse 019 de novembro e remataron o 11 de decembro de 1895, ocupando en total dez días. A listaxe elaborada por Calvelo incluía 66 testemuñas de cargo -basicamente as que asinaran a denuncia perante notario- e 40 de descargo. Practicamente toda vila de Cuntis e a súa contorna estaba implicada nun conflito que a dividiu -non sabemos exactamente por onde- e que sen dúbida viviu con particular intensidade. Unha división que posiblemente foi máis causa que consecuencia do conflito, aínda que este contribuíse a intensificala.

Das 40 testemuñas de descargo citadas -entre elas o alcalde, varios concelleiros e outros notables locais-, case todas acudiron a declarar, se exceptuamos as que o propio interesado solicitou que fosen excluídas por diversos motivos: teren prestado xa declaración no expediente, residiren lonxe ou poderen ser sospeitas de parcialidade. Desta forma pretendía abreviar uns trámites que se estaban demorando en exceso.

A primeira declaración correspondeu a Antonio Ares Magariños, que se pronunciou así: "que nada tiene que decir contra la conducta moral y política del maestro D. Hermenegildo Calvelo y que nunca le vio borracho, ni oyó decir que se le diese cencerrada alguna, ni tampoco que haya tenido disturbios algunos en su familia, ni oyó tampoco que en la información recibida ante el Ayuntamiento se haya atemorizado a nadie". O resto das persoas pronunciáronse en termos similares: negaban os cargos e achegaban, no seu caso, datos que contribuían a sustentar o argumentario desenvolvido polo mestre no seu extenso escrito de descargo. Miguel González, por exemplo, dixo saber "de público que el presbítero D. Pedro Castro estuvo algún tiempo privado de celebrar misa y D. Nicolás Garrido fue trasladado a otro punto y privado de la capellanía que aquí disfrutaba".

Particular interese teñen as palabras de dona Juana Rabuñal Gómez, nai do acusado, pois un dos cargos facía referencia a que era maltratada polo seu fillo. Tiña máis de 60 anos - unha boa parte dos declarantes non sabían a súa idade con precisión: os aniversarios parecían ter nesa época moito menos relevancia da que tiñan os cabodanos-, estaba viúva, dedicábase aos seus labores e non asinaba por non saber facelo. $O$ seu testemuño foi o seguinte:

que ha vivido y vive casi constantemente con su hijo el Sr. Calvelo y si alguna vez ha salido por temporadas de su domicilio lo ha hecho por razones de índole privada que cree nadie tiene derecho a averiguar, razones que no son suficientes por desconocidas para suponer disentimiento alguno entre la que declara y su hijo, pues ni éste le faltó jamás al respecto, ni la que dice al cariño que le debe, ni en la vida privada surjió [sic] jamás con familiar alguno pendencia de ningún género y esta gratuita 


\begin{abstract}
suposición lastima por si sola a la declarante y la aflige sobremanera: que la aflige todavía más, si cabe, el que se invoque su nombre contra su mismo hijo hasta el punto de haberla hecho presenciar en su casa en el mes anterior el hecho de que un señor que supo se llamaba D. Miguel Nine, asociado de otro caballero, se permitió preguntarle si su hijo la maltrataba, si él se embriagaba, si le había matado una perrita y si las criadas le habían faltado, preguntas que todo caballero bien nacido debe considerar que son dolorosas y ofensivas para una madre, dicho sea con el debido respeto: que por consiguiente nunca tuvo queja alguna de su hijo: que este vivió con su esposa algunos años, lo mismo que hizo la declarante después de quedar viuda, durante algún tiempo, mas luego su hija política Dā Manuela Villanueva empezó a causarles grandes disgustos, hasta el punto de presentar demanda de divorcio contra el marido y se separó bruscamente de él sin motivo alguno razonable, rechazando después todos los medios de avenencia que durante mucho tiempo se le propusieron, haciendo así imposible la vida en común, pero sin culpa alguna de su hijo: que oyó decir que su referida hija política se había puesto de acuerdo con D. Joaquín Barreiro para perseguir al Sr. Calvelo, pero esto le parece increíble, dada la esquisita [sic] educación que aquella recibió, y sólo lo atribuye a anomalías de temperamento, que sin duda pretenden aprovechar los que quieren hacer de su hijo una víctima de burdas intrigas de localidad.
\end{abstract}

Das 66 testemuñas de cargo, só tres acudiron ao xulgado, negándose as restantes a facelo, por consideraren que non estaban obrigadas. Manuel Castro oficiou á Xunta provincial para preguntar se efectivamente así era, e a contestación foi que debía limitarse a convocar as persoas relacionadas por Calvelo e a rexistrar as declaracións das que tivesen a ben prestalas.

Dous dos tres comparecentes asinaran a denuncia notarial. Un deles, Manuel Piñeiro, dicía agora "que nunca vio a dicho sr. Calvelo privado de bebida y que ignora si esta circunstancia consta en el acta que suscribió en unión de otros en veintitrés de Diciembre del año anterior, porque cuando llegó para firmarla ya la habían leído". ${ }^{21} \mathrm{O}$ outro, Restituto Vázquez, sostiña que o único que pretendera coa súa sinatura fora defender o presbítero Nicolás García, cuxa conduta cuestionara o mestre.

A terceira testemuña de cargo que acudiu ao xulgado foi José Maria Lorenzo, o presbítero cubano que dirixira unha instancia ao reitor, e seguramente estaba preocupado polas consecuencias que podían derivarse do seu contido -se cadra, os seis nenos dos que dicía estar encargado só existían na súa instancia, como sostiña Calvelo-. En realidade nada lle constaba en contra do mestre, e se escribiu ao reitor foi ao ditado de Joaquín Barreiro, José Fariña e os dous presbíteros, cuxos informes soubo despois que eran "apasionados y efecto de intrigas políticas". El descoñecía inicialmente tales intrigas, por ter chegado recentemente de Cuba. E xa postos a declarar, tamén ouvira dicir "que el D. Joaquín Barreiro se pusiera de acuerdo con la señora del sr. Calvelo para perseguir a éste".

Rematadas as demoradas e prolixas dilixencias, o expediente foi sometido a consideración do inspector provincial, que propuxo 0 sobresemento, por non estimar probados os cargos -non concedía credibilidade a uns denunciantes que lle atribuíran a el mesmo actos dos que non era responsable- (Documento 4). Moi distinta foi a valoración da comisión nomeada pola Xunta provincial -integrada polos vogais Victoriano Encinas, Emilio Álvarez

\footnotetext{
${ }^{21}$ Foron varias as persoas que nas súas declaracións utilizaron -seguramente inducidas, como adoitaba suceder nestes casos- unha expresión que se prestaba a equívocos, malia pronunciarse co ánimo de defender a Calvelo: nunca o viran "privado de bebida".
} 
Giménez e Joaquín López Paratcha- para informar ao pleno desta corporación sobre os feitos investigados, pois propuxo o traslado de Calvelo a outra escola da mesma categoría (Documento 5). A Xunta provincial acordou facer seu "en todas sus partes" o anterior informe, e así llo comunicou á Reitoría o 27 de xuño de 1896. O reitor, á súa vez, remitiu o expediente a Gorgonio Hueso, que propuxo ao Consello universitario o sobresemento (Documento 5). Este órgano colexiado, en sesión celebrada o 25 de novembro de 1896, asumiu 0 informe e a proposta do relator. ${ }^{22}$

Contrasta o parecer dos tres relatores nomeados pola Xunta provincial co dos inspectores da Coruña e Pontevedra, e nomeadamente co do director da Escola Normal de Santiago. Estes entendían que non se probaran os cargos de natureza moral e profesional que se lle apuñan a Calvelo, malia recoñeceren, particularmente os inspectores, que coa súa actitude durante a tramitación do expediente agraviara a persoas que lle dificultarían o exercicio da profesión en Cuntis -Tomás Luciano Carreira mesmo apostaba, en ben do ensino, polo traslado-. Aqueles, entre os que se achaban Victoriano Encinas (profesor da Normal de Pontevedra) e Emilio Álvarez Giménez (profesor do Instituto), dous dos redactores de Los Maestros de España, publicación defensora dos intereses do maxisterio ${ }^{23}$, non concedían ningún mérito aos descargos do mestre e ás probas que se esforzara en reunir para defenderse, que parecen contundentes, cando menos nalgúns extremos. Lendo o seu informe xorden dúas hipóteses, que non son necesariamente excluentes. Primeira: os seus autores sabían sobre 0 mestre de Cuntis máis do que constaba no expediente, que non era pouco. Segunda: estaban predispostos en contra del, como tamén parecía estalo Miguel Nine, o seu compañeiro de corporación. Sexa como for, de se ateren ao contido literal do expediente, sería difícil non recoñecer a inconsistencia de cando menos algunhas imputacións e a animosidade e mesmo as falsidades dos seus inimigos, certificadas por dous inspectores provinciais.

Paralelamente ao expediente gobernativo, desenvolveuse o proceso xudicial a que foi sometido Calvelo como consecuencia da demanda presentada polas persoas ás que presuntamente inxuriara, que mereceu a seguinte sentenza na Audiencia de Pontevedra, segundo comunicou a Xunta provincial ao reitor:

\begin{abstract}
Hallamos: que debemos condenar y condenamos al procesado D. Hermenegildo Carballo Rabuñal, a la pena de 5 años, 2 meses y 8 días de destierro a 25 kilómetros de la Villa de Cuntis; multa de 500 pesetas, y al pago de dos octavas partes de costas; quedando sujeto en caso de insolvencia a sufrir un día más de destierro por cada cinco pesetas que deje de satisfacer de la multa y costas de la acusación privada, con la limitación establecida en el artículo 5ํ del Código penal. Le absolvemos por los otros seis delitos de injurias de que ha sido acusado, declarando de oficio las otras seis octavas partes de costas. ${ }^{24}$
\end{abstract}

Hermenegildo Calvelo comezou a cumprir o desterro o 6 de xuño de 1896. Tivo que abandonar, xa que logo, a escola de Cuntis, aínda que tiña dereito a servila mediante

${ }^{22}$ Libro de Actas do Consello universitario da Universidade de Santiago, AHUS, libro A-180.

${ }^{23}$ As biografías de Los Maestros de España reproducíronse entre 2004 y 2007 nas páxinas de Sarmiento con estudos introdutorios a cargo de Anxo S. Porto Ucha, José Luis Iglesias Salvado, Víctor M. Juan Borroy e Narciso de Gabriel.

${ }^{24}$ AHUS, Ensino primario, caixa 121. 
substituto. Entre os tres candidatos propostos pola Xunta provincial, a Reitoría nomeou para o cargo a José Rivas Solla.

01 de decembro dese mesmo ano, o reitor comunicou á Xunta provincial o resultado do expediente disciplinario: sobresemento sen nota desfavorable para o interesado. Mais como este estaba condenado a desterro, aconselláballe que solicitase outra escola de igual categoría e soldo mediante permuta, "sin que se entienda que a ello se le pueda obligar con perjuicio de los derechos que tiene adquiridos como Maestro propietario de la escuela de Cuntis". Tratábase dunha opción legal sempre aberta, á que se adoitaba recorrer cando existían enfrontamentos graves entre o mestre e unha parte dos veciños, e para Calvelo, que estaba cobrando a metade do salario -a outra metade correspondía ao substituto-, resultaba particularmente vantaxosa. Así que noso home aceptou o consello, e 020 de xaneiro de 1897 foi nomeado por permuta para a escola de Mourente, da que tomou posesión ao día seguinte.

Finalmente, os rivais de Calvelo conseguiron desfacerse del, aínda que fora por vía xudicial no canto de gobernativa, e seguramente non aforraron en pólvora cando a Audiencia de Pontevedra fixo pública a súa sentenza.

\section{Mourente}

A comisión nomeada pola Xunta provincial de Pontevedra optaba, como xa sabemos, por trasladar o mestre a outra escola "en la que pueda demostrar que no es a él achacable la enemiga que le tienen gran parte de los vecinos del pueblo en que hoy ejerce" (Documento 5). Pois ben, na parroquia de Mourente -no seu día concello autónomo e na data que nos ocupa integrada no de Pontevedra- tivo a posibilidade de demostrar que así era, e certamente non a aproveitou.

O 2 de xullo de 1897, o xornal pontevedrés La Opinión faise eco, baixo o título "Escuelas abandonadas", dun texto aparecido en El Socialista de Madrid atacando a Hermenegildo Calvelo, "que se desata contra nosotros desde El Áncora, periódico carcatólico de Pontevedra, con tal cúmulo de disparates, que si tuviéramos tiempo y espacio, sería cosa de copiarlos todos para que el lector pasara un rato divertido." Calvelo, advirte El Socialista, fora mestre da escola de Cuntis, aínda que non a frecuentaba moito, e nesa data érao da de Mourente, onde "sigue brillando por su ausencia". La Opinión, pola súa parte, advirte que o mestre, librepensador reconvertido ao catolicismo, "cobra y no trabaja, al revés de sus colegas, que trabajan y no cobran." 25

Calvelo era, en efecto, colaborador de El Áncora, onde publicaba unha sección co incisivo título de "Guerrillas", dedicada a atacar todo o que cuestionara o catolicismo e 0 conservadorismo. 012 de xuño de 1897 dedicou o artigo a criticar a máxima sustentada

\footnotetext{
${ }^{25}$ Sempre que non se sinale outra procedencia, neste apartado basearémonos na documentación que se conserva sobre o segundo expediente gobernativo no AHUS (Ensino primario, caixa 121), e nomeadamente nun resumo das dilixencias practicadas e no informe que a Reitoría enviou á Subsecretaría do Ministerio de Instrución Pública e Belas Artes o 18 de xuño de 1903, do que se conserva un borrador e unha copia.
} 
polos socialistas no voceiro que editaban en Madrid, "bastante leído en Pontevedra": "El ideal de nuestro Partido es la abolición de las clases sociales". Don Hermenegildo non gustaba de tal abolicionismo, que suporía a desaparición tanto dos canteiros como dos médicos, e conduciría ao "aniquilamiento de la sociedad". Malia ser absurda, algún proveito podía tirarse desa teoría: fronte a un "capitalismo divorciado de Dios, despiadado y sin entrañas", a "fiera socialista" constituía "un dique, un medio providencial, para castigar la faticidad de los poderosos y facilitar el retorno de la sociedad al seno de Cristo, que a ricos y a pobres estrecha entre sus brazos, y a unos y otros une por medio del amor, no por medio del interés." Como é ben sabido, conclúe o autor, Deus é quen de tirar bens de males.

O reitor puxo a denuncia xornalística en coñecemento da Xunta provincial e ordenoulle que determinase cal era o seu fundamento. Esta contestou que todo obedecía á "animosidad" de La Opinión contra o mestre, que fora redactor deste xornal e pasara a selo de El Áncora, pois non se comprobara a existencia de abandono nin existían queixas por parte dos veciños.

Que os veciños non estaban satisfeitos evidenciouse nunha instancia dirixida por máis de 80 ao reitor 029 de decembro dese mesmo ano. De feito, segundo o resumo do expediente, as denuncias iniciáronse poucos días despois de tomar Calvelo posesión da súa nova escola, aínda que no informe remitido pola Reitoría ao Ministerio non se mencionase esta circunstancia. Laiábanse de que non cumpría coas súas obrigas profesionais, e desde logo non facía escola polas tardes, malia as advertencias do inspector neste sentido, de forma amistosa primeiro e oficial posteriormente. Debido á presión das autoridades superiores, comezou a abrir a escola polas tardes, mais non co propósito de ensinar, senón de dedicarse a ler e a escribir -seguramente aproveitaría para redactar as súas "Guerrillas"-, de modo que moitas familias só enviaban os seus fillos á escola pola mañá, sesión que adoitaba iniciarse cunha hora de atraso. A Xunta provincial, ademais de advertilo da necesidade de axustarse ao horario regulamentario, lembroulle que estaba obrigado a residir no distrito escolar e a render contas sobre a adquisición de material docente.

Así as cousas, o 27 de xaneiro de 1898 o vicerreitor Cleto Troncoso oficiou á Xunta provincial para que abrise un novo expediente gobernativo, como así se fixo. Calvelo solicitou que se lle permitise examinar as dilixencias practicadas para contestar aos cargos e presentar testemuñas para xustificar os descargos, polo que necesitaba a ampliación do prazo establecido a estes efectos, accedéndose a todas as súas demandas.

Mentres tanto, unha parte da prensa seguía denunciando o abandono dun mestre que en xaneiro de 1899 resultou elixido vicepresidente da Asociación provincial do maxisterio pontevedrés. ${ }^{26}$ Foi atacado con especial agresividade desde as páxinas de El Magisterio Gallego. Algún dos seus redactores seguramente tiña contas pendentes co noso protagonista, e decidiu recorrer aos recursos estilísticos que este adoitaba empregar:

¿Pero qué, el famosísimo D. Hermenegildo Calvelo, exescribiente, y Maestro de Mourente, tiene ya otro expediente por cumplir bien con sus deberes? ¡Qué cosa tan rara! Calvelo, el escritor, filósofo, pedagogo, y sobre todo esto, buen hijo, como que vive con su madre, además del expediente que se le

${ }^{26}$ El Diario de Pontevedra, 9 de xaneiro de 1899. 
formó en Cuntis, siendo Maestro de allí, tiene ya otro expediente en Mourente, por ser buen Maestro, o todo es un expediente?

De seguro que alguna intriga anda por medio, porque lo que es Calvelo, es incapaz de cometer hechos, como cometen ciertos hijos que arrojan a su madre de la casa en que vive, o no hacen vida con otras personas.

Calvelo, no. Es un dechado de virtudes. ${ }^{27}$

En todo caso, a partir do 16 de outubro de 1899 xa non precisaba dar clase: a Sociedade de Agricultores de Mourente abrira unha escola no lugar de Casasnovas e os veciños acordaran retirar os seus fillos do ensino público. Se cadra foi esta circunstancia a que 0 animou a presentarse a unhas oposicións convocadas en 1901 para cubrir as prazas de mestre das escolas anexas ás Normais de Lugo, Ourense e Santiago. Polo que sabemos, non conseguiu facerse con ningunha delas.

Desde a Reitoría reclamouse 0 expediente á Xunta provincial en maio e agosto de 1898 e en novembro de 1899, aínda que as dilixencias non foron remitidas ata 013 de xullo de 1901, tres anos e medio despois de se iniciaren os trámites. O inspector propuxera a separación o 26 e maio de 1898, e a corporación provincial non se pronunciará, optando polo traslado, ata 011 de xullo de 1901, é dicir, tres anos máis tarde! Escusaba 0 adiamento argumentando que cesaran os vogais encargados de elaborar o informe...

Daquela xa non estaba Maximinio Teijeiro Fernández á fronte da Reitoría, senón Francisco Romero Blanco, aínda que por esas datas parece que exercía o cargo o vicerreitor Cleto Troncoso. A el se dirixiu, a título particular, o inspector Salvador de J. Ponsoda o 13 de xullo de 1901. Advertíao do expediente que proximamente chegaría ás súas mans sobre o mestre de Mourente, $0 \mathrm{cal}$, "desde que se posesionó apenas puso los pies en la escuela y desobedeció y se burló de la Junta, de la Inspección y de la parroquia." A xente queixábase acotío, e se non afloraran máis denuncias fora "porque a alguien no convino". Achegaba o último informe do párroco, segundo o cal o mestre había "unos tres años próximamente que aquí no presta personalmente enseñanza a los niños." Durante algunhas tempadas a escola estivera a cargo de substitutos e noutras pechada, o local deteriorábase cada vez máis e o material era moi escaso. 0 inspector decidiu non o unir este informe ao expediente "para no agravar más los cargos".

O reitor, considerando que nos tres anos transcorridos desde a apertura do expediente 0 mestre tivera tempo de emendarse, que as propostas de sanción eran diverxentes, que el non era partidario do traslado como medida disciplinaria, e que antes de optar pola separación cumpría valorar detidamente os feitos, acordou que procedía facer novas indagacións. Claro que se tomou o seu tempo para chegar a esta conclusión -10 meses- e ordenar á Xunta provincial que, unha vez máis, informase sobre o mestre de Mourente (14 de maio de 1902).

A corporación provincial limitouse a remitir o informe do inspector. Este consideraba que os resultados educativos e instrutivos da escola "son altamente satisfactorios, y la organiza-

${ }^{27}$ El Magisterio Gallego (Santiago), 26 de xuño de 1898. 
ción, métodos y procedimientos empleados responden a un fin práctico, y están en armonía con los modernos adelantos pedagógicos." Como a Xunta non manifestaba cal era o seu parecer, foi interrogada expresamente, contestando que "nada le consta en contrario de cuanto dicho Sr. Inspector manifiesta en relación a estos últimos tiempos." Mais como o reitor temía que este, por ser novo na provincia, "se hubiese equivocado en su informe", acordou darlle un tempiño para se aclimatar, pois non se podía prescindir do seu criterio neste tipo de procedementos administrativos. A maiores, solicitou informes particulares.

O 31 de xuño de 1903, cansos de sufrir durante sete anos "un verdadero calvario", e visto que as súas demandas non eran atendidas nin pola Xunta provincial nin pola Reitoría, varios veciños de Mourente dirixíronse ao ministro de Instrución pública. Fixérono nos seguintes termos:

Y permítanos V. E. que manifestemos nuestro asombro al observar que un maestro de escuela que tiene en completo abandono sus deberes, que no se corrige y que sigue aún hoy siendo un profesor deplorable y funesto, para salvarlo se apela al insólito medio de averiguar como se portó durante [el] largo tiempo en el que sufrió retraso la tramitación de lo diligenciado.

Si nuestra Administración pública no hace gala en general de la rapidez en la marcha de los asuntos, la de la enseñanza de Santiago procede peor, siendo baldías las reglas de nuestro procedimiento administrativo encaminadas a abreviar los trámites de todo asunto.

¡Es donosísima la idea del Rectorado de Santiago!

El Maestro Calvelo resulta casi una víctima y jes claro! el encargado de patentizarla fue el Inspector de escuelas recién nombrado, el cual, por esta circunstancia, no pudo penetrarse del daño y de la responsabilidad moral contraída al proceder con ligereza indisculpable, originándose de su informe otro sobreseimiento para Calvelo.

¡Y el Rectorado, verdadero autor de toda esta maniobra, acuerda el sobreseimiento del expediente gubernativo, sin intervención del Consejo Universitario!!...

¡Triste condición la de los pueblos que pagan una enseñanza que no tienen! ¡Y lamentables autoridades que así sancionan la conducta inmoral de un maestro que es de entre lo peor, lo más malo bajo todos los aspectos!

Llegó la parcialidad a dar vista del expediente al Calvelo, que lo examinó a sus anchas; proponiendo una información testifical que se ejecutó, trámite, por cierto, no consentido a infelices maestros huérfanos de toda recomendación con sueldos de 250 pesetas y separados por el Rectorado de Santiago con arreglo al artículo 171 de la ley de Instrucción pública.

O Ministerio enviou esta instancia ao reitor, que segundo os veciños xa decidira pola súa propia conta sobreser 0 caso, ${ }^{28}$ ordenándolle que informase sobre 0 asunto e remitise o expediente. Este así o fixo o 18 de xuño de 1903, prometendo que reuniría o Consello universitario para que formulase unha proposta de resolución -nas actas deste órgano non consta que o expediente se sometese á súa consideración-, que na súa opinión debería ser a separación do mestre, sempre e cando, engade, "se comprobasen oficialmente las pruebas que contra él existen."

De modo que, cinco anos e medio despois de se abrir o expediente, aínda había que comprobar os feitos denunciados... Á vista deste proceder, sería difícil cuestionar a ne-

${ }^{28} \mathrm{Na}$ copia do informe citado na nota 21 rexístranse unhas "observaciones" que semellan confirmar este feito, xa que nelas consta que o reitor remitiu o expediente, mais "no acompaña copia de su orden sobreseyéndolo." 
cesidade de facer unha reforma en profundidade da administración do sistema educativo español, que parecía estar á altura do "desastre" de 1898. Como denunciaban os rexeneracionistas, o caciquismo enseñoreábase da administración pública. E non só da municipal, senón tamén da provincial e universitaria.

Non dispoñemos de información sobre o curso dos acontecementos a partir dese momento, aínda que si coñecemos o desenlace final do expediente, do que se fixo eco a prensa en xaneiro de 1904. O Ministerio acordou amoestar tanto o presidente e os vogais da Xunta provincial de Instrución pública de Pontevedra como o reitor da Universidade de Santiago "por las irregularidades observadas en la tramitación de dicho expediente", e "separar inmediatamente del Magisterio oficial a D. Hermenegildo Calvelo y Rabuñal". ${ }^{29}$ Foron varios os diarios que publicaron esta Real orde, e El Noticiero Gallego comentaba as dúas decisións adoptadas. Sorprendíase da primeira, por ter formada unha opinión favorable das dúas institucións afectadas, e respecto da segunda recoñecía que o mestre podería ser merecedor dalgún castigo, mais consideraba desmedida "la separación absoluta del Magisterio primario, sin pasar por la advertencia o la traslación." E concluía advertindo aos subscritores sobre as "medidas radicales que ahora usa la Superioridad."30

\section{Traxectoria posterior}

Aos poucos días de ser separado, Calvelo foi nomeado pola Deputación de Pontevedra "auxiliar temporero" para prestar servizos en labores administrativos relacionados coa instrución pública, o que puña de manifesto a protección que lle dispensaban algunhas autoridades provinciais. ${ }^{31}$ Sabemos que en 1906 residía en Goián (seguramente se trataría da parroquia de Tomiño), onde dirixía un colexio de ensino primario, aínda que descoñecemos desde e ata cando. ${ }^{32}$ Sete anos máis tarde, 0 alcalde de Vigo encomendoulle a instrución dos reclusos da cidade olívica, cunha retribución de 1.000 pesetas anuais. ${ }^{33}$ Así pois, continuou vinculado ao ensino durante algún tempo. De feito, tentou retornar ao maxisterio público, mais a súa solicitude de rehabilitación profesional será desestimada. ${ }^{34}$

A súa outra actividade profesional foi, como xa dixemos, o xornalismo. Parece ser que se iniciou no oficio en El Libredón, editado en Santiago de Compostela, de cuxa dirección se fixo cargo cando Alfredo Brañas tivo que deixala e a proposta deste. ${ }^{35}$ Ao se fusionar con El Pensamiento Gallego, de orientación carlista, o líder rexionalista -que nos últimos

\footnotetext{
${ }^{29}$ La Educación (Madrid), 31 de xaneiro de 1904.

${ }^{30}$ El Noticiero Gallego. Semanario destinado a fomentar los intereses morales y materiales del Magisterio de primera enseñanza (Pontevedra), 25 de xaneiro de 1904.

${ }^{31}$ El Diario de Pontevedra, 12 de febreiro de 1904.

32 El Noticiero de Vigo, 9 de setembro de 1906.

${ }^{33}$ El Correo de Galicia (Santiago), 17 de xaneiro de 1913.

${ }^{34} \mathrm{O}$ reitor comunicoulle esta resolución ministerial o 2 de agosto de 1905 (AHUS, Ensino primario, caixa 121).

${ }^{35}$ A Gaceta de Galicia (Santiago) informaba 04 de febreiro de 1887 que abandonara a redacción de El Libredón para atender "sus ocupaciones" -daquela traballaba na Secretaría da Universidade-, e El Lucense escribía 027 de abril do mesmo ano que asumira provisoriamente a dirección.
} 
anos da súa vida abrazou o carlismo ${ }^{36}$ - publicou unha carta aberta en varios xornais, dirixida a Hermenegildo Calvelo, para desvincularse dunha operación da que declaraba discrepar radicalmente:

Y digo esto no porque sienta que un periódico católico y digno como El Pensamiento prospere y florezca, sino porque el público creería que en el seno de El Libredón había carlistas en estado de larva, lo cual me disgustaría bastante, pues mientras yo estuve al frente de El Libredón, éste se ha mantenido siempre independiente, sin afiliarse a ningún partido político conocido. ${ }^{37}$

En Pontevedra traballará en El Áncora, que tamén dirixirá, cando menos durante algún tempo ${ }^{38}$ e que abandonará en $1899 .{ }^{39}$ Desde este xornal polemizará con outros diarios. Algúns dos seus contrincantes aludían nestas liortas aos seus problemas xudiciais e administrativos. Así o facía Javier Valcarce Ocampo, nun enfrontamento onde non faltaron os retos:

Apelo al público, y a mis compañeros de los demás diarios locales, para que juzguen su conducta de $V$. y la mía, aunque a mí me basta con poder decir, con la frente muy alta, que nunca he sido procesado, ni desterrado por injurias, ni se me ha formado expediente en oficina alguna por faltas en el cumplimiento de mi deber, cosa que $V$. no puede decir respecto a su persona. ${ }^{40}$

A terceira cidade onde exercerá o xornalismo será Vigo. Nela dirixiu primeiro La Voz de Vigo, que apareceu en febreiro de 1908 e respondía aos intereses de Angel Urzáiz y Cuesta, ${ }^{41}$ e posteriormente El Restaurador, de orientación xaimista. ${ }^{42}$

Finalmente, o Circulo Católico de Ourense reclamouno en 1913 para que se puxese á fronte da publicación que pretendía promover para defender os intereses do conservadorismo provincial, que recibirá o nome de El Diario de Orense. ${ }^{43}$ Os seus ingresos complementábanse cos que lle fornecía outra ocupación, a de empregado da Delegación de Facenda. Desempeñará unha e outra función ata a súa morte, producida en 1918.

A mortífera gripe dese ano puxo fin a unha vida que xa perdera moito alento por mor da afección pulmonar que viña padecendo o noso home. As publicacións periódicas deron conta do suceso e gabaron a traxectoria do compañeiro, cuxo funeral foi sufragado polo Círculo Conservador e a Asociación da Prensa. "Murió el Sr. Calvelo pobrísimamente. Sábese que estaba casado, aunque se ignora la residencia de su esposa, pues el finado era incomunicativo y retraidísimo."44 "Calvelo era uno de los mejor documentados y más sesudos periodistas gallegos. Hubiese vivido en Madrid, favorecido un poco por la suerte, y ha-

\footnotetext{
${ }^{36}$ Ramón Maiz, Alfredo Brañas (Vigo: Galaxia, 1983).

${ }^{37}$ El Correo Gallego (Ferrol), 3 de maio de 1887.

${ }^{38}$ El Diario de Pontevedra, 4 de agosto de 1897.

${ }^{39}$ La Correspondencia Gallega (Pontevedra), 26 de abril de 1899.

${ }^{40}$ Carta aberta publicada en El Diario de Pontevedra, 17 de xullo de 1898.

${ }^{41}$ El Eco de Santiago aludía á súa aparición o 13 de febreiro de 1908.

${ }^{42}$ El Correo Gallego (Ferrol) informaba o 20 de xuño de 1913 que se suspendera provisoriamente a publicación deste xornal.

${ }^{43} \mathrm{O}$ primeiro número do diario conservador ourensán foi saudado por El Diario de Pontevedra 08 de xaneiro de 1914.

${ }^{44}$ El Norte de Galicia (Lugo), 2 de outubro de 1918.
} 
bría sido uno de los más conocidos y gloriosos escritores españoles."45 "Murió pobremente en el Hospital, sin dejar más bienes que unos cuantos libros, [...] uno de los periodistas más cultos y batalladores con que contaba Galicia. [...] Descanse en paz."46

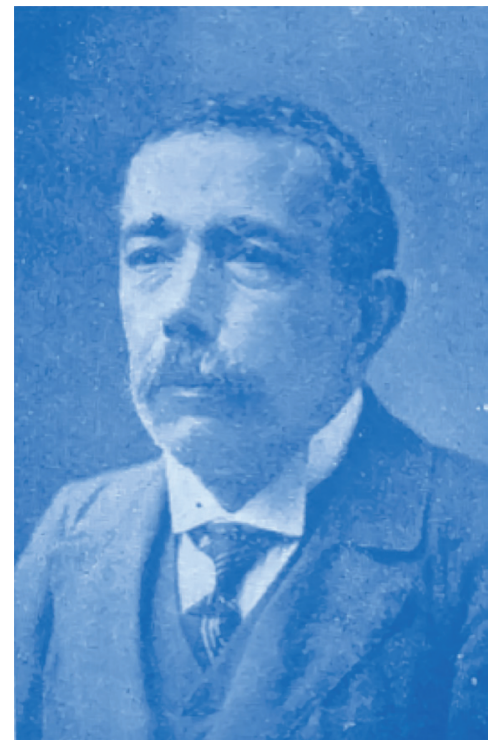

Hermenegildo Calvelo retratado por Vida Gallega en 1917

45 Vida Gallega (Vigo), 10 de outubro de 1918.

${ }^{46}$ Gaceta de Galicia (Santiago), 1 de outubro de 1918. 